\title{
Credit Service System Design to Promote Beijing Citizens' Green Travel Behavior
}

\author{
Zhenwei You1, Jian Liu' ${ }^{2}$, Xiaohe Sun1, Yuying Wei', Yaoyao Yuan1 \\ ${ }^{1}$ School of Digital Media and Design Arts, Beijing University of Posts and Telecommunications, Beijing, China \\ ${ }^{2}$ School of Design Arts, Beijing University of Technology, Beijing, China \\ Email: ^ljym66@163.com
}

How to cite this paper: You, Z. W., Liu, J., Sun, X. H., Wei, Y. Y., \& Yuan, Y. Y. (2020). Credit Service System Design to Promote Beijing Citizens' Green Travel Behavior. Art and Design Review, 8, 148-158.

https://doi.org/10.4236/adr.2020.83011

Received: June 4, 2020

Accepted: June 9, 2020

Published: June 12, 2020

Copyright $\odot 2020$ by author(s) and Scientific Research Publishing Inc. This work is licensed under the Creative Commons Attribution International License (CC BY 4.0).

http://creativecommons.org/licenses/by/4.0/

\begin{abstract}
As Beijing develops, problems such as traffic congestion and resource consumption are growing more prominent. Advocating green travel and building an ecologically responsible society are of great significance to construct an urban ecological environment. The goal of this study is to define how to design a service system according to Beijing's citizens' travel behavior motivations, to effectively promote citizens' green travel behavior and enhance their environmental awareness. Through a questionnaire, the author learned about Beijing's citizens' travel behaviors and green travel attitudes. Applying Beijing's citizens' travel behavior characteristics and the human motivation theory, the study identified behavioral motives suitable for inducing changes in travel behavior. A Beijing green travel credit service system has been proposed based on the travel motivations of citizens. This service system can effectively transform green travel behaviors into habits and improve citizens' environmental awareness of travel. Multiple departments, including government agencies, will play vital roles in this service system, and their cooperation and interaction will have a significant impact on the service's implementation.
\end{abstract}

\section{Keywords}

Service System Design, Green Travel, Behavioral Motivation, Environmental Awareness, Credit Mechanism

\section{Introduction}

Beijing has a huge population, with no less than 6.1 million daily commuters, which increases traffic congestion. In Beijing, the average Traffic Performance Index is 8.32 (severe congestion), and the maximum is 9.68 (Zhao \& Wang, 
2018). The public transportation system has a dense bus network and an increasingly complex subway system. The road design has not only made it inconvenient for citizens to travel but also has caused environmental problems. Exhaust emissions and dust have a direct impact on air quality, and noise affects people's lives. From 1998 to 2017, Beijing reduced the intensity of emission pollutants each year through management policies, such as restricting the total number of motor vehicles on the road (Xiao, 2003), staggering the rush hour shift, reducing license plate issuance, and promoting new-energy vehicles. However, the core problem remains: the number of private cars in Beijing has exceeded capacity, and traffic congestion has become the norm, leading to more emissions. Beijing's traffic and environmental problems cannot be solved by the current restrictions alone. Therefore, solutions must start with the citizens by improving their environmental protection awareness, strengthening their green travel guidance, and reducing their private car use.

When interacting with a service system, the user only interacts with its touch points. Based on the tether model of interaction between users and the service system, the touch points are closely related to options and feedback in the service system (Tether, 2011). Combining behavioral motivation with options and feedback in the service system can motivate users to subconsciously change their behavior and then consciously change their awareness. The motivation-based design makes users more receptive and generates spontaneous and active behaviors (You \& Liu, 2017). The goal of this study is to define how to design a service system according to Beijing's citizens' travel behavior motivations, to effectively promote citizens' green travel behavior and enhance their environmental awareness.

\section{Environmental Awareness and Beijing's Citizens' Travel Behavior}

In order to understand Beijing's citizens' travel behavior and environmental awareness, a questionnaire was used to collect information on the relationship between environmental protection attitudes and travel methods, ecological awareness of different travel methods, attitudes toward gasoline-powered vehicles, attitudes toward new-energy vehicles, frequently used travel methods, and travel method convenience. A total of 459 valid questionnaires were collected and revealed that 441 (96\%) of the people needed to travel more than once a day.

The statistical results showing the correlation between environmental protection and travel methods are found in Table 1 . About $30 \%$ of the sample population believed that environmental protection and travel methods are related. About $60 \%$ of the sample population rated the correlation as "strong" or "very strong”. This reflects that Beijing's citizens' macro awareness of green travel is not strong enough.

The environmental awareness for different travel methods is shown in Table

2. Only $1.7 \%$ of people believed that gasoline-powered motorcycles are envi- 
ronmentally friendly, $4.8 \%$ believed their own cars are environmentally friendly, and $4.1 \%$ believed taxis are environmentally friendly. In general, these results indicate that the sample population possessed an accurate judgment of whether various travel methods are environmentally friendly and an understanding of the necessary standards for environmental protection.

The statistics showing the sample population's degree of approval for using gasoline-powered vehicles and new-energy vehicles are shown in Figure 1 and Figure 2. Most people had no objection to traveling in gasoline-powered vehicles or new-energy vehicles, but compared to gasoline-powered vehicles, new-energy vehicles were more acceptable to the sample surveyed. This indicates that people tended to be environmentally friendly. However, Figure 1 shows that more people (65.8\%) were neutral about using gasoline-powered vehicles, and $26.6 \%$ approved of using gasoline-powered vehicles; gasoline-powered vehicles have the advantages of convenient refueling and long battery life, which encourage users to continue using them.

Table 1. The correlation between environmental protection and travel methods.

\begin{tabular}{ccc}
\hline degree of correlation & frequency & percentage \\
\hline Very low & 15 & $3.3 \%$ \\
Low & 18 & $3.9 \%$ \\
General & 155 & $33.8 \%$ \\
Strong & 183 & $39.9 \%$ \\
Very strong & 88 & $19.2 \%$ \\
total & 459 & $100 \%$ \\
\hline
\end{tabular}

Table 2. The environmental awareness for different travel methods.

\begin{tabular}{lll}
\hline $\begin{array}{l}\text { Which the travel method do you think is environmentally } \\
\text { friendly }\end{array}$ & frequency & percentage \\
\hline $\begin{array}{l}\text { Taking the self-balancing scooter is environmentally } \\
\text { friendly }\end{array}$ & 109 & $23.7 \%$ \\
$\begin{array}{l}\text { Taking the electric motorcycle is environmentally } \\
\text { friendly }\end{array}$ & 86 & $18.7 \%$ \\
$\begin{array}{l}\text { Taking the bus is environmentally friendly } \\
\text { Taking the gasoline-powered motorcycle is environmentally }\end{array}$ & 278 & $60.6 \%$ \\
friendly & 8 & $1.7 \%$ \\
Taking your private car is environmentally friendly & 22 & $4.8 \%$ \\
Taking the subway is environmentally friendly & 348 & $75.8 \%$ \\
Taking car sharing is environmentally friendly & 105 & $22.9 \%$ \\
Walking is environmentally friendly & 344 & $74.9 \%$ \\
$\begin{array}{l}\text { Taking sharing bikes or motorcycles are environmentally } \\
\text { friendly }\end{array}$ & 279 & $60.8 \%$ \\
Taking a taxi is environmentally friendly & 19 & $4.1 \%$ \\
\hline
\end{tabular}




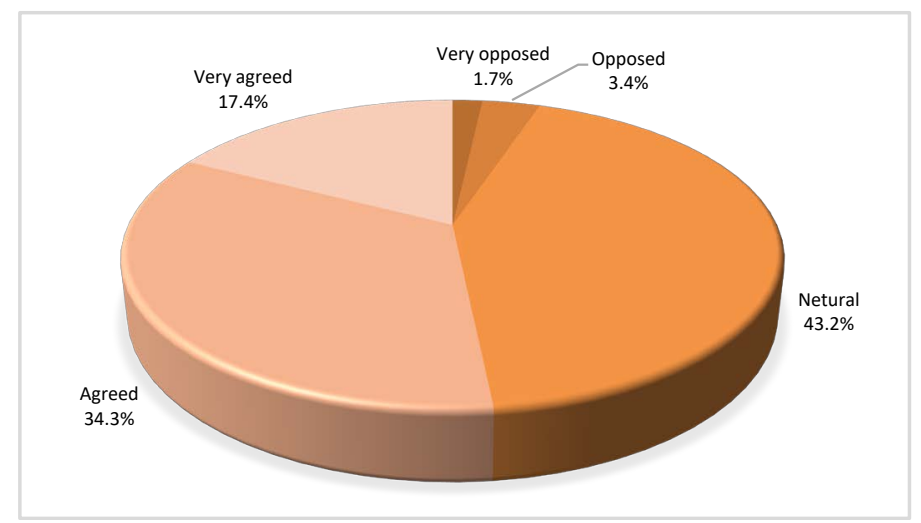

Figure 1. Approval degree of using gasoline-powered vehicles.

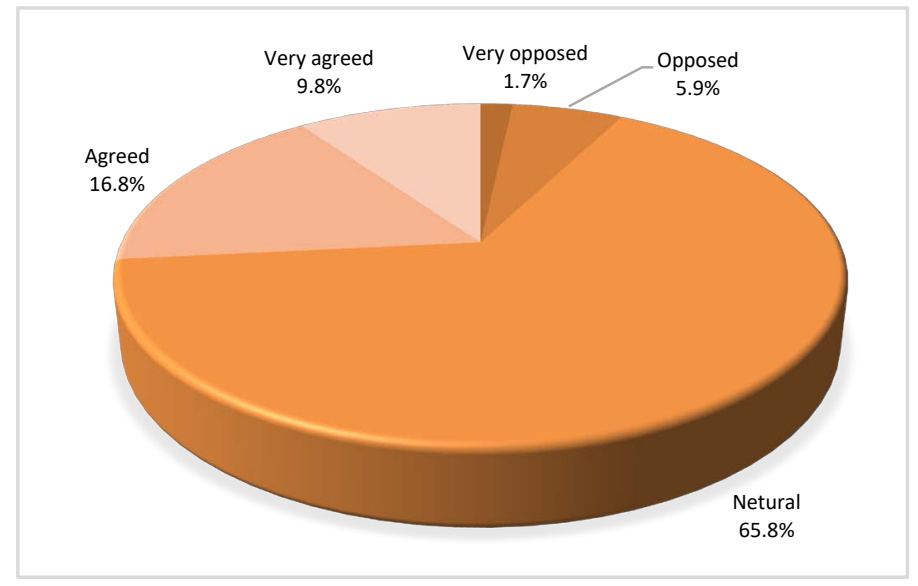

Figure 2. Approval degree of using new-energy vehicles.

Figure 3 and Figure 4 show the statistics for frequently used travel methods and the recognition of their convenience. As many as $18.3 \%$ of people frequently traveled by private cars, which is in sharp contrast to the $4.8 \%$ of people (Table 2 ), who believed that private cars are environmentally friendly. Although people consciously knew that private cars are not environmentally friendly, they still chose them for travel.

Although only $5 \%$ of those surveyed considered subways to be the most convenient and $50.8 \%$ considered electric motorcycles to be the most convenient transportation modes (Figure 4), the frequently used travel methods results indicate the opposite: $3.5 \%$ surveyed used electric motorcycles and $45.8 \%$ used subways. Thus, subjects chose travel methods that were simpler, easier, faster, more affordable, and not weather-dependent.

The questionnaire included open-ended questions to evaluate the reasons people chose private cars and what caused poor public transportation experiences. The results showed that conditions such as social status, financial ability, comfort, convenience, changes in fuel prices, road restrictions, and free public transportation influenced whether the sample population chose private cars as a travel method. Heavy traffic, insufficient road planning, and inefficient traffic flow were the main causes of poor public transportation experiences that people reported. 
The questionnaire's summary indicated that Beijing's citizens have a limited sense of environmental protection; instead, elements like a method's simplicity, ease, speed, affordability, comfort, and convenience are the most important criteria for choosing travel methods. The criteria Beijing's citizens use for choosing travel methods can also be understood as their motivation.

\section{Behavioral Motivation}

Motivation is a person's desire and the actions taken to achieve a goal. Everyone's behavior is driven by motivation, which can prompt individuals to challenge themselves and achieve goals (Maslow, 1987). Therefore, it is important to understand the motivations behind human behavior. Proactive decisions show both increased efficiency and success rates. There are three main motivations for human behavior: happiness, interest, and incentives.

Happiness means different things to different people. However, it generally comprises feelings of joy, pleasure, contentment, and love. Enjoyable activities are motivating and pleasing, and happiness can make a person feel positive and help them ignore their troubles and sorrows (Nettle, 2006). Isen's psychological research shows that happiness can expand thinking and promote creative thinking (Ashby, Isen, \& Turken, 1999).

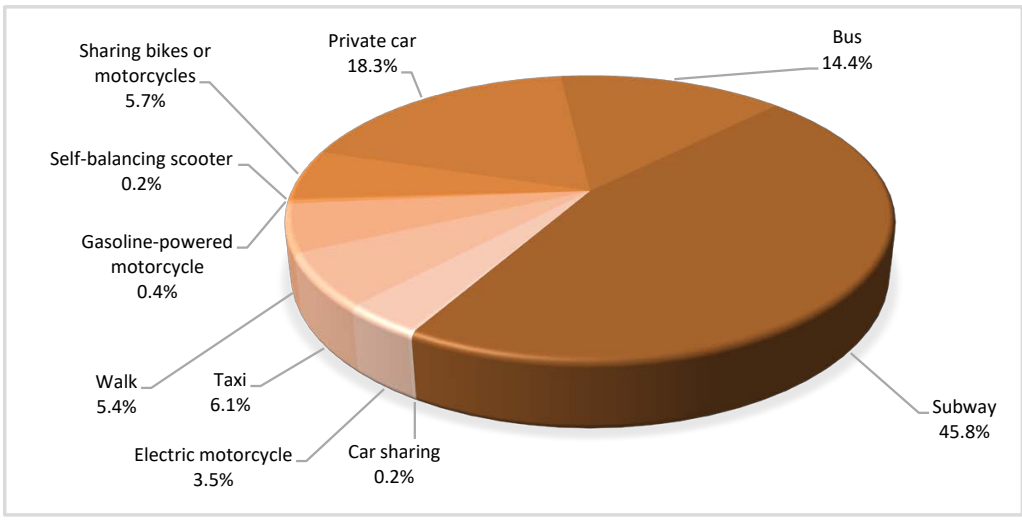

Figure 3. Frequently used travel methods.

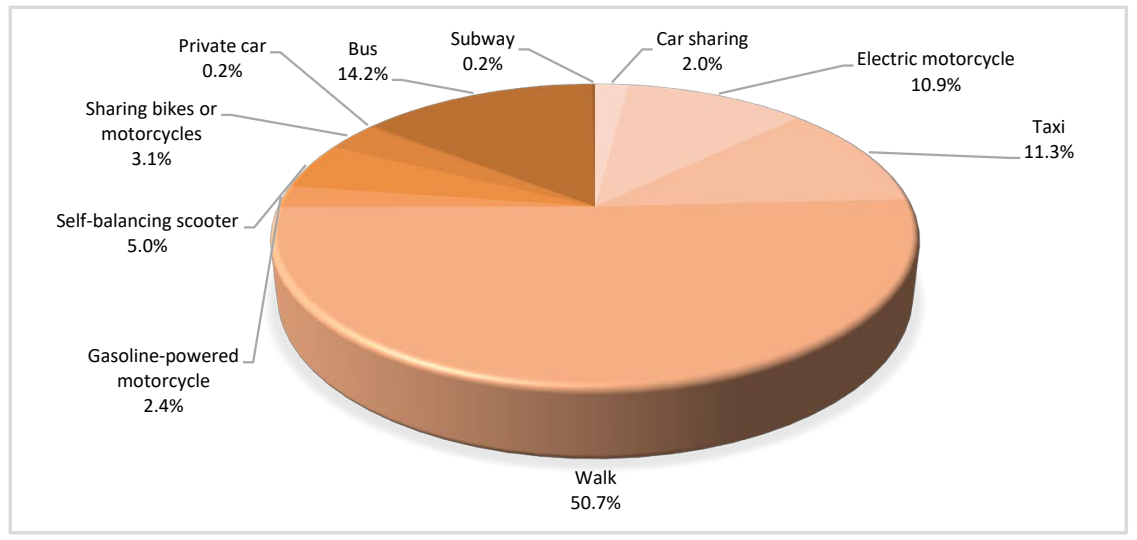

Figure 4. Recognition of the convenience of traffic travel methods. 
Interest is a very powerful motivator. Children actively engage in interesting activities. Interest inspires not only children but also adults, who immerse themselves in pleasurable activities that offer no material rewards (Deci, 1992). In addition, attractive things are influential. They can make people feel good, think more creatively, and provide motivation to find solutions. For example, when playing computer games, players can complete each task very patiently (Norman, 2004). Thus, people who are interested in work are motivated to do well (Vroom, 1999).

In many cases, incentives are the most important behavioral motivators. The more benefits, the more needs can be met. Gaffney summarized seven main incentives that can drive human behaviors: money, time, safety, success, difference, image, and enjoyment (Gaffney, 2005).

The main behavioral motivators are summarized in the literature survey and the questionnaire's results identifying the criteria Beijing's citizens use to choose travel methods. These motivations affect Beijing's citizens' travel behaviors: simplicity, ease, speed, affordability, comfort, convenience, happiness, fun, safety, success, difference, and image (Figure 5).

\section{The Existing Green Travel Service System for Citizens}

There are several existing green travel service systems for citizens. Through studying these cases, we can define the service system design strategies more effectively.

Alipay launched an AI green travel solution in 2019, using cloud computing, AI, and other technologies. It comprehensively improved the intelligent scheduling of public transportation, customized travel and network optimization to improve the speed of public transportation operations and user travel experience, and promote efficient, green travel (Ye, 2019). In the same year, Foshan from Guangdong and Alipay collaborated to launch an electronic bus ride code. People who used this code could enjoy the first daily ride free of charge, purchase a monthly or weekly electronic bus pass, and enjoy a $50 \%$ discount on code ride, get ant forest energy and other services. These benefits encouraged citizens to choose low-carbon emission modes of public transportation (Wang, 2019).

In 2010, Beijing established a free bicycle system in the Chaoyangmen area. The service used a credit system to ensure that users returned the bicycles on time; the service was free to attract users (Zhao, 2010). However, due to system

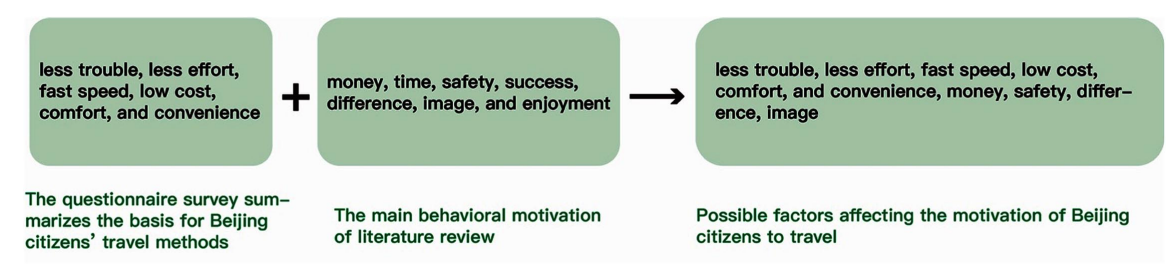

Figure 5. Motivation summary about influencing the Beijing citizen travel behavior. 
maintenance difficulties, free bicycle services are no longer available in Beijing. Bike-sharing services are now relatively established, and they have become primary green travel tools. Thus, for a green travel service system to succeed, it must achieve three goals: provide efficient and convenient travel, low-cost service options, and ease of operation.

\section{Design of Beijing's Green Credit Service System Based on Behavioral Motivation}

We built a green credit system. Based on this green credit system, we designed a service system combining the travel motivations.

\subsection{The Green Credit Service System Described}

Credit systems are a commonly used commercial model. The initial credit starts at zero. When the user logs in or uses the service, the credits accumulate and cannot be deducted. The credit system greatly stimulates users to make full use of services or to make purchases to accumulate as many credits as possible. Because there are various ways for citizens to travel, travel behaviors can be assigned in the form of green credits so that these behaviors can be quantified. Such a system will be convenient for citizens to make comparisons and promote their green travel. At the same time, credits can also be used as a travel behavior inventory, facilitating a more intuitive and clearer understanding of personal travel behaviors.

In order to distinguish travel behaviors, the calculation rules for green credits are as follows: driving private cars neither deducts nor adds points, taking taxis or ride-hailing is +0.5 points, car sharing is +1 point, taking a bus is +3 points, taking the subway is +4 points, driving an electric motorcycle is +4 points, bike sharing is +5 points, and walking is +5 points per kilometer. Green credits cannot be deducted.

The advantage of the green credit system lies in its flexibility without forcing citizens to choose green travel but allowing them to retain diverse travel options. Citizens can choose a travel method according to their needs. This system's design aligns with the goal set by this research to create a program where users unconsciously change their behavior and then consciously change their awareness.

\subsection{Content Design Based on Behavioral Motivation}

The proposed green credit system must recognize the motivations that may affect the travel behaviors of Beijing citizens (Figure 1). Three motivations, money (affordability), convenience, and self-image, provided the starting points for the service's content design. Citizens can reduce expenses through trading green credits. They can use these credits in exchange for commodities, free public transportation, free tickets for sharing bicycles, parking, etc. By connecting with multiple information platforms (such as WeChat, Official Accounts, etc.) and 
trading platforms (such as electronic transportation cards, Alipay, etc.), citizens can quickly and conveniently obtain green credits and use them for spending, making life more convenient. Daily green credit rankings on social software will encourage people to recognize their travel behaviors and encourage self-evaluation and personal environmental awareness. The system can also calculate users' vehicle carbon emissions during a day of travel and compare them with the country's average to encourage people to choose a greener way of travel. Green credits can directly generate benefits and also satisfy users' subtle competitive psychology. Similar to WeChat steps, the model will help users to naturally and effectively evaluate their choices, improving their environmental awareness.

\subsection{Design Concretization}

The design project was concretely improved by using the three aspects of the platform, the specific functions implemented, and its background management. The detailed design project list (Table 3 ) and service design system diagram (Figure 6) are as follows:

Thus, the green credit service system is a comprehensive service system centered on a social platform that integrates government agencies, enterprises, public welfare organizations, and media (Figure 6). The core of the system's operation depends on government support and cooperation among various agencies.

\subsection{Storyboard}

Use the storyboard to enter the scene and fully understand the relationship between users and the green credit service system (Figure 7).

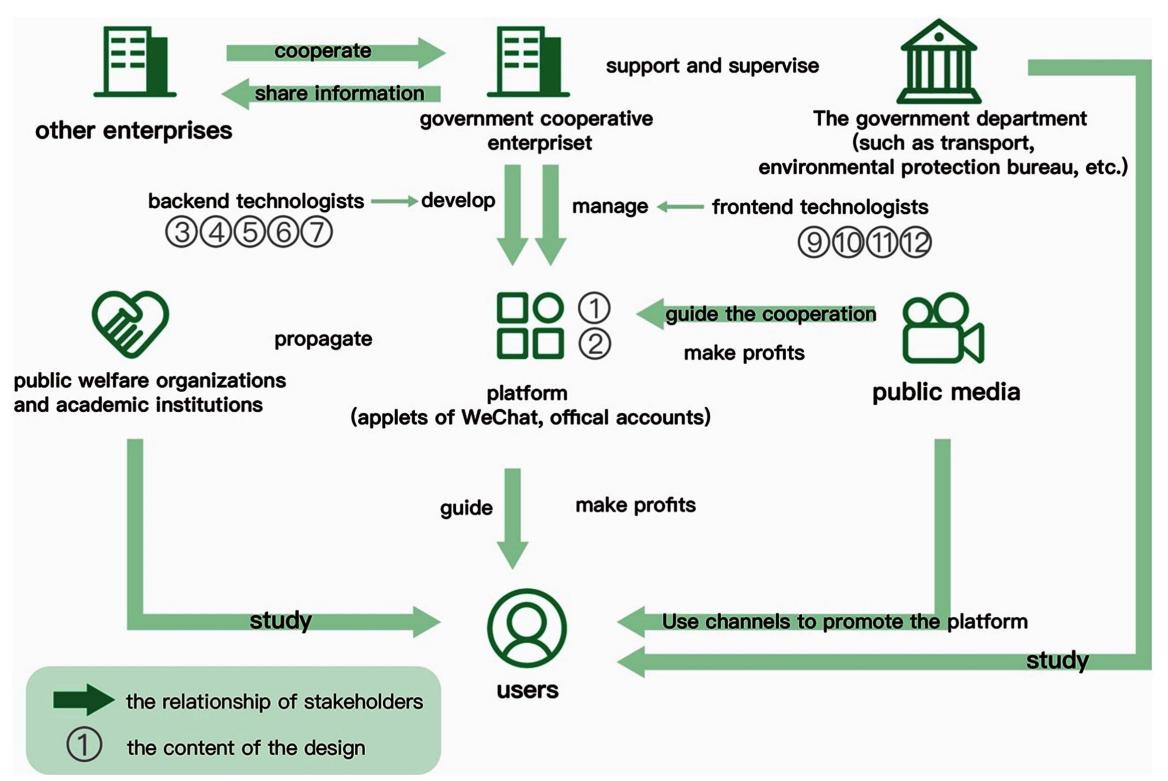

Figure 6. The system map of green credits service system design. 

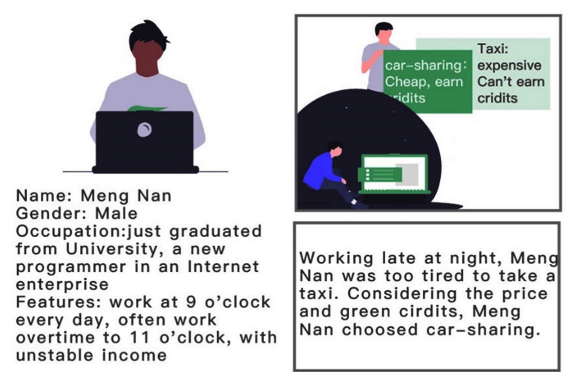
Nan was too tired to take taxi. Considering the price and green cirdits, Meng Nan choosed car-sharing. overtime to 11 o'

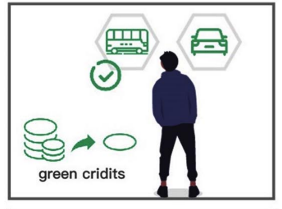

After working overtime all day, Men
carpool again. But recently, there are so man coupons to redeem that there are few green cridits left. Considering that the
original price of carpooling is too expensive, he hoosed the bus.

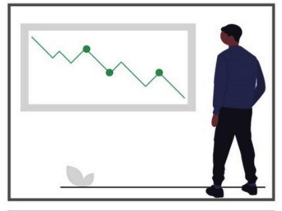

Back home, lying in bed, recently he used too many green cridits. After looking at the social ranking, he bottom, so he had to mak it up quickly. So he planed to take the bus or subway for the next few days.

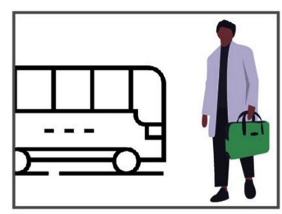

The next day when he got p to work, Meng Nan 作 taken a taxi last night, so
he took the bus and the ubway to save up green cridits.

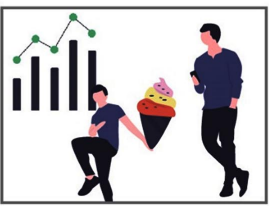

In the next few days, Meng Nan always cares about his whether he has exceeded his friends. He bought an ce cream to reward himself using the money saved by the pub
transportation.

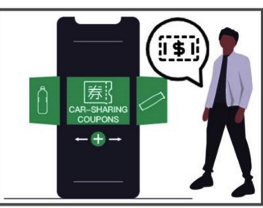

At the end of the month, he was short of money.
After working overtime at night, he even felt that car-sharing was expensiv. So Meng Nan used green
cridits to exchange for car-sharing coupons.
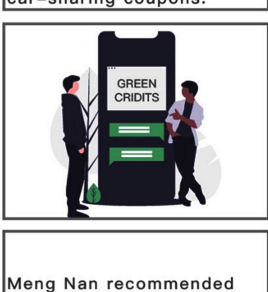
the 'green cridits' app to the company's 'carpoolin priends', which became workers.

Figure 7. The storyboard of green credits service system design.

Table 3. A detailed list of design project.

\begin{tabular}{|c|c|c|}
\hline & Name & Description \\
\hline \multirow{5}{*}{ Platforms } & 1) applet of wechat & $\begin{array}{l}\text { "Green credits system" uses WeChat applet to develop, and forms a closed loop with } \\
\text { WeChat and official accounts, users do not need to download additional app. }\end{array}$ \\
\hline & 2) Official accounts & $\begin{array}{l}\text { Be used with small programs; make publicity of } \\
\text { environmental protection, travel and life; Mainly for young commuters. }\end{array}$ \\
\hline & $\begin{array}{l}\text { 3) collect user travel } \\
\text { information }\end{array}$ & $\begin{array}{l}\text { Collect used vehicles; Share the data of the electronic } \\
\text { transportation card, Alipay and the city bus app. }\end{array}$ \\
\hline & 4) Statistical integral & The user green credits statistics. \\
\hline & 5) Ranking & $\begin{array}{l}\text { The ranking of users' green credits every day is the same as the "WeChat Steps" strategy, } \\
\text { and they "compete" with the friends of the friends list. }\end{array}$ \\
\hline
\end{tabular}

Functions

6) Calculation and display of transportation carbon emissions

7) Official accounts push

8) Credits trading

9) data management

10) User management

Management* 11) System guarantee

12) Business management
According to individual travel, combined with the carbon emission calculation and publicity, the user's daily carbon emissions from transportation are obtained and compared with the national average of users.

None

Consumption of green points in exchange for commodities, free tickets for public transportation, free tickets for sharing bicycles, parking tickets, etc.

It is necessary to collect the data of users' use of different types of vehicles on different platforms to complete the storage, analysis, statistics, management and uploading of data.

Manage user permissions, user status, user behaviors, user feedback processing, etc.

System operation monitoring, data update process

monitoring, and user behavior monitoring ensure the stable operation of the system.

Automatically publish data sets, complete credits redemption and other functions, and adjust point strategies based on user feedback and users' use of vehicles after the credit system

*: It is necessary to pay attention to the coordination and interaction between different functional departments in the design process. Data collection, sharing, processing, and feedback require good management. 


\section{Conclusion}

By integrating the credit concept, the green credit system will cultivate users' green travel habits in positive and interesting ways such as through credit acquisition and exchange, personal credit ranking, etc., so that users can obtain basic benefits and feel fulfilled from using green travel. Simultaneously, using green travel can greatly reduce Beijing's traffic congestion, especially during rush hours. Transportation-induced carbon emissions knowledge can familiarize users with this environmental protection concept and provide a quantitative objective understanding of personal behaviors, thereby reducing carbon emissions and improving environmental awareness.

The system does not use laws and regulations to force citizens to adopt green travel, but the credits will attract users. The system is easy to develop and maintain, is social software compatible, easy to popularize, and simple to use. Through cooperation with other industries, researchers can categorize citizen travel behaviors, providing valuable data on these behaviors and environmental issues. The system's early publicity will initially require increased funding, which, to a certain extent, will affect the traditional rental industry's and the ride-hailing businesses' revenues. However, these industries can follow the green travel trend to transform and adopt more environmentally friendly models to provide better services.

When analyzing social issues, service design usually starts from a people-oriented perspective. Excellent design not only meets human needs but also creates value, so it is more readily accepted by users; service design always analyzes each problem in detail to solve it in an orderly, holistic and systematic way. Service design enables intangible services to be presented to the public in tangible forms. Through the design practice of public services, users have improved experiences when using intangible social public resources, making design practices go to the public. The green credit service system design aligns with supporting society's long-term development and works with citizens to build public interest in preserving it (Gao, 2015).

\section{Acknowledgements}

This paper is supported by the Projects supported by the Beijing Social Science Foundation Grant No. 17YTB022.

\section{Conflicts of Interest}

The authors declare no conflicts of interest regarding the publication of this paper.

\section{References}

Ashby, F. G., Isen, A. M., \& Turken, A. U. (1999). A Neuropsychological Theory of Positive Affect and Its Influence on Cognition. Psychological Review, 106, 529-550. https://doi.org/10.1037/0033-295X.106.3.529 
Deci, E. L. (1992). The Relation of Interest to the Motivation of Behavior: A Self-Determination Theory Perspective. In K. A. Renninger, S. Hidi, \& A. Krapp (Eds.), The Role of Interest in Learning and Development (pp. 43-70). Mahwah, NJ: Lawrence Erlbaum Associates, Inc.

Gaffney, S. (2005). 7 Benefits That Drive Human Behavior.

Gao, Y. (2015). From the Perspective of Public Services to Discuss the Value of Service Design. New Art, 36, 84-90.

Maslow, A. H. (1987). Motivation and Personality. New York: Harper \& Row.

Nettle, D. (2006). Happiness: The Science behind Your Smile. New York: Oxford University Press. https://doi.org/10.7861/clinmedicine.6-2-214

Norman, D. (2004). Emotional Design: Why We Love (or Hate) Everyday Things. New York: Basic Book.

Tether, B. (2011). Service Design-A UK Perspective. Tokyo: Service Design International Workshop.

Vroom, V. (1999). Management and Motivation (2nd ed.). London: Penguin.

Wang, R. (2019). Since Today, Foshan Bus Can Use Alipay to Ride the Bus, the First Order Is Free for Free Every Day. Sinhua Web.

Xiao, F. (2003). In Order to Improve the Quality of the Atmospheric Environment, Beijing 19 Seats (Inclusive) and below "Yellow Label" Passenger Cars Begin to Restrict Traffic in September. Commercial Vehicles, No. 10, 63-64.

Ye, C. Q. (2019). Alipay Releases AI Green Travel Solution. Financial Technology Era, 10, 91.

You, Z. W., \& Liu, J. (2017). Changing Human Behavior through Service System Design. Terre Haute: Science and Engineering Publishing Company.

Zhao, X., \& Wang, R. Q. (2018). Analysis of Causes and Countermeasures of Urban Traffic Congestion in Beijing. Modern Economic Information, No. 34, 490-492.

Zhao, Y. R. (2010). Free Bike System Gets Rolling on 100 Sets of Wheels. China Daily. http://www.chinadaily.com.cn/china/2010-03/02/content 9525138.htm 